\title{
Cultivation and Management of English Talents Based on Dynamic Quality Control \\ Li Wei
}

Xinyang College of Agriculture and Forestry ,Xinyang,Henan Province,464000

\begin{abstract}
Keywords: Dynamic quality control; English talents; cultivation;
\end{abstract}
\begin{abstract}
The cultivation of the English talents who manage the English industry, which can not be got after accepting college education,but with the international and domestic English industry environmental changes, who need to enrich their knowledge and summarize the experience of the long-term training process. In this paper, it takes the concept of dynamic quality control as the cutting point, combined with the explanation of the guarantee system of English talents in the higher education such ad colleges and universities,discussing the cultivation path of English talents from the restructure of English discipline system, the reform of the teaching contents and methods, as well as the open of the experimental teaching center,and the aspect of encouraging the innovation of students, so as to discuss the specific cultivation model for English talents, building a new innovative system of cultivating food talents, exploring a stronger operational path of cultivating the innovative food talents.
\end{abstract}

\section{Introduction}

With the development of China's economy, English industry in China has got a rare opportunity for its development, it has become an unavoidable problem for us to think how to cultivate a large number of applied professional talents to meet the needs of the development of food industry. Universities and colleges bear the three basic functions, namely, cultivating talents, scientific research, social services, while cultivating talents is its the most basic function. The research on the condition of the food industry and the need for food talents within the food industry groups showed that with the traditional food science and higher education's talents cultivation mode, the thinking mode is mainly the to imitation and reproduction type, many people are lack of innovation consciousness, who have less innovation abilities, thus the quality, knowledge and ability of talents can not keep up with the economic development as well as the technological and social development, especially the graduates majored in food who are lack of the innovation consciousness, with weak innovation abilities, which has become a bottleneck restricting factor to limit the development of food industry. Therefore, the establishment of talents cultivation system of strengthening students' innovation consciousness, innovation thinking and innovation ability has become the top priority for food science and talents cultivation in higher education. Thus, food science education in colleges and universities must be based on the cultivation of innovative food talents.

\section{The Connotation of Dynamic Quality Control}

In any circumstances, there always exists difference, although making the same products by a certain standard, which can be known as the variation. The reasons for causing the variation of the quality include the following main aspects: Man, Material, Machine, Method, Environment, which can be shorted for 4M1E. The quality of product is by making, instead of by testing. If there is no stable process to manufacture, the high quality of products will be difficult to reflect. Process quality control is the core of quality control, which is the research emphasis of quality engineering for many years. The dynamic quality control system based on inspection and optimization, which is mainly aimed at solving the problem of process quality control. 


\section{Dynamic Quality Control System Model Based on Inspection and Optimization}

According to system theory and control theory, the essence of quality control is a kind of process control system, while quality control system can be considered as a decision making center for quality control, by continuously measuring the quality characteristics if the system, making comparison with the quality objectives, so as to go on with quality decision-making and feedback the decision- making information to all stages of the system, which can be shown in Fig.1

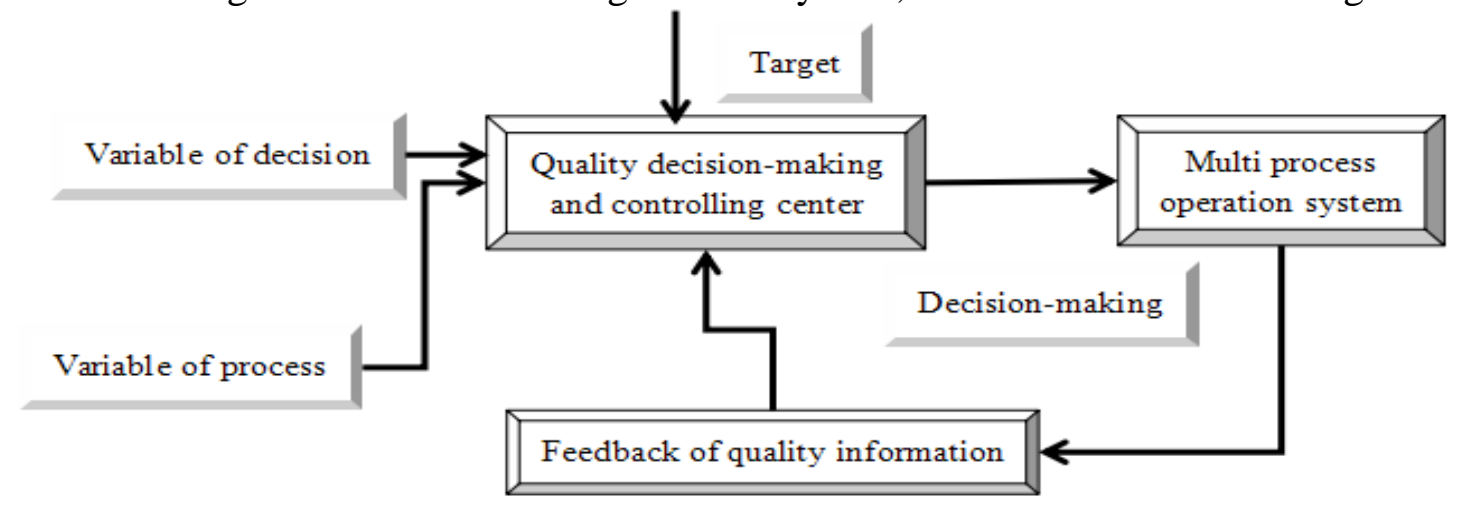

Fig. 1 The Process of Quality Control

\section{The Quality Guarantee System for English Talents of Higher Education}

The quality guarantee system of higher education refers to the system "that can enable consumers of higher education ( such as government, society, families and educators ) to be satisfied with the quality of training provided by the institutions of higher education, scientific research as well as social service, so as to built up the organic system with organization, procedures, processes and resources and other elements that can be interconnected and restricted with each other by using the principle of the system".[1] Higher education quality guarantee system can be divided into two types according to the different implementation subjects,namely, the internal guarantee system and external guarantee system.[2] The internal guarantee system of higher education quality guarantee system refers that the implementation of continuous and effective quality control system conducted by the school itself, so as to improve the quality, which is mainly about the internal quality guarantee activities of the higher education. The external guarantee system refers to the monitoring system that is established to monitor the quality of school education, which can be composed by the specific regional or national institutions. The main task of these institutions is to lead, organize, implement and coordinate the higher education quality appraisal activities and supervise the internal quality of higher education, so as to guarantee the activities, the members can be including the experts outside of the field of higher education, who are generally appointed by government or industry organization.[3] As far as the content of higher educational quality is concerned, it can be divided into three aspects, namely, the inputting guarantee, process guarantee and outputting guarantee.[4]

\section{The Cultivation Path for English Talents}

\section{The Reconstruction of Physical Education Discipline System}

On the basis of the platform of general education curriculum, the core curriculum of the subject should be designed so as to determine the core of the curriculum of the platform. People should take full use of the advantages of universities and colleges, exploring the advantages of the existed professional fields and resources, as well as the other related disciplines, so as to promote the principle of developing cross discipline and building complex majors. In an effort to build a "platform course" based on the platform of the subject curriculum such as: chemistry, food analysis and testing, food microbiology, which also takes food technology as the core and high - tech subject as the forefront. Building the "platform courses" as the base with the teaching modules of "Course 
Groups", so as to reflect the flexible learning requirements. Such as taking "chemistry" as the basis, breaking the old course teaching mode of inorganic chemistry, organic chemistry, analytical chemistry and physical chemistry, so as to integrate the four chemical teaching together into one basic chemistry curriculum, which also put its emphasis on its basic, comprehensive and advanced feature, so as to form the basic chemistry teaching module; moreover, breaking old course teaching mode of food chemistry, food technology, food analysis and food microbiology, integrating the professional teaching as a whole, constituting a kind of English discipline teaching system in food science. In addition, the establishment of the elective course in the module allows students cross grade and major to choose courses, which can gradually establish and realize the talent cultivation plan that can reflect the students personalized training program based on the instructive teaching plan.

\section{Reform of the Teaching Content and Mode of English}

According to the requirement of innovation education, combined with the specific characteristics of students, as well as the developing direction, so as to play the guiding role of teachers, finding out the programs that can be tailored for the student individuality development, focused on the selection of some special top students, making specific programs the students in accordance with their aptitude, making training plans for the personalized feature, as well as special training course during the period of teaching and training; in the course of innovation training for the food talents, a lot of the original bilingual teaching materials can be used with a large number of teaching methods such as: discussing, heuristic study, as well as case study, through the creation of specialized research training courses, students can go into teachers' lab or into the research group as soon as possible, who can take part in the scientific research and practice more, together with the teaching process, so as to explore and the new ways of teaching and research training course more actively.

Based on the popularization of multimedia teaching, we can make full use of the Internet as the basis of modern teaching method, expanding the teaching resources, so as to stimulate students' participation in teaching and expand the teaching time and space, which can improve the teaching quality.[5] Methods such as the establishment of the school network teaching platform, the construction of new century network course with the outstanding teaching course ware introduced by the Education Department; students can also use their own website set up a message board, as well as the establishment of a network learning zone, which can be acted as a communication channel between teachers and students. In the experimental teaching, the introduction of "PBL" teaching method can be introduced (see Fig. 2), so as to break the traditional teaching mode. It is often determined by the teacher with the problem of the experiment, the problem is generally required to have the feature of openness and authenticity, students should understand the experimental principle, operation and so on through the inquiry of information, hands-on work, mutual discussion and self reflection. Teachers can play a guiding role during this process. In this kind of experiment, students can take the initiative to take part in the activities as the participants, thus the learning interest can be greatly improved, which also can cultivate students' quality, for example: the skills of solving problems, the ability of team cooperation, as well as the ability of accessing and evaluating information. 


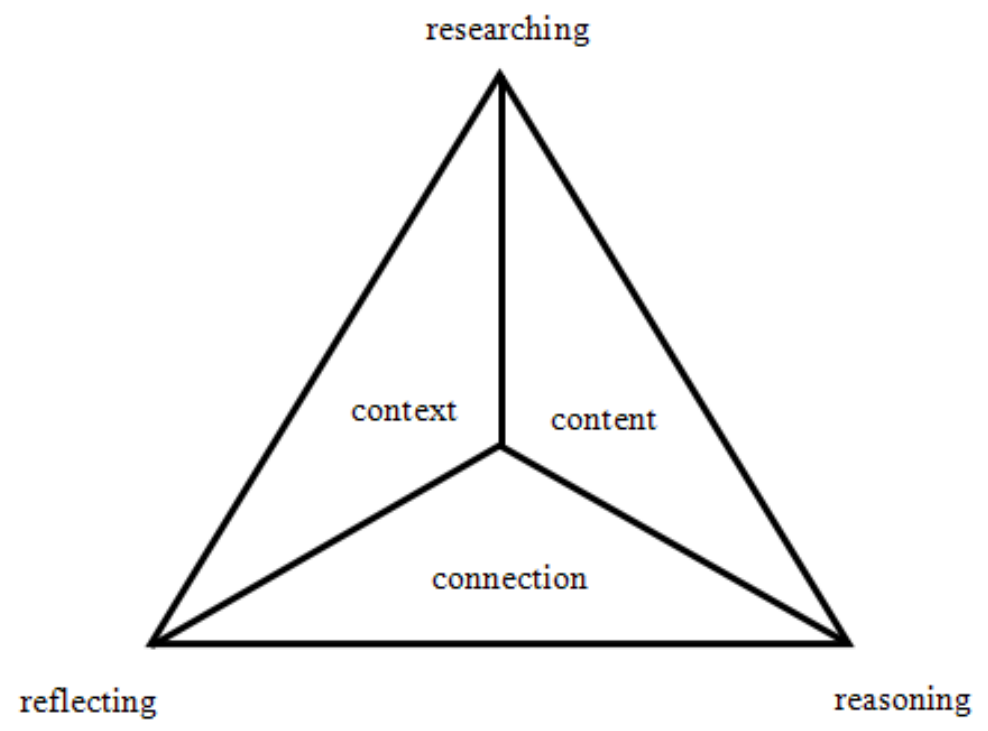

Fig. 2 Diagram of PBL Teaching Method

\section{Opening the Experimental Teaching Center, Encouraging Students with Self Innovation}

Opening the experimental teaching center can provide free stage for the students who can play independent innovation role in cultivating the potentiality of top students. And the school LAN can be regarded as the support and platform of the educational management system. Thus, it can achieve open experimental teaching management network, all the base equipment, open topics, teachers research direction can be open on the Internet, students can log to the experimental platform, browse and download web course ware and multimedia images as well as data. No matter what kind if majors and grades, students can make an appointment on the Internet, according to the direction of their own interest, so as to apply for their own open innovation experimental subjects and guiding teachers. At the same time, it can promote students to bring their own problems into the experimental teaching center, which can encourage them to have bold innovation. Through the opening experiment teaching center, students can make independent innovation experiment, which not only can make students establish scientific research ideas, carry out scientific research work, cultivate scientific research team work spirit, but also can make students cultivate the awareness of learning literature retrieval, data collection methods and academic standards, so as to improve the ability of finding problems, analyzing problems and solving problems. Therefore, it can mobilize the enthusiasm of students as well as the initiative participation in scientific research, which can play a great role in promoting the cultivation of the innovative Englishs talents in 21st century.

\section{Conclusion}

Compared with the English industry environment of the developed countries, the development of China's English industry still has much room to be improved. Among them, one of the decisive factors for the development of English industry is cultivating the management talents in the future that can decide whether China's English industry can keep up with the international tendency. Governments, universities and social enterprises should shoulder the responsibilities and obligations of cultivating English talents. Therefore, it should have reasonable development by utilizing the existed research, teaching, marketing resources, join multiple aspect ratios, through multi-channel, with high efficiency, so as to cultivate food industry talents, who also had a practical, scientific spirit, so as to cultivate food industry talents for China's English industry market at different levels.

\section{Reference}

[1]Chrysanthe Demetry and John A. Orr. 2009. Quality Assurance in Engineering Education in the United States Lance Schachterle, Engineering Education Quality Assurance, Part 3, pp:163-180. 
[2]A.V.Valiulis and D.Valiulis. 2009. Engineering Education Quality Assurance: The Essential Pillar of Higher Education Reform in Lithuania. Engineering Education Quality Assurance, Part3, pp:191-198.

[3]Andreas Hoecht. 2006. Quality Assurance in UK Higher Education: Issues of Trust, Control, Professional Autonomy and Accountability .Higher Education, vol.51, pp:541-563.

[4]A. Chuchalin, O. Boev and A. Kriushova.2009. Quality Assurance in Engineering Education and Modernization of Higher Education in Russia. Engineering Education Quality Assurance, Part 3, pp:87-95.

[5]Hao V. Le and Kim D. Nguyen. 2009. Quality Assurance in Vietnam’s Engineering Education. Engineering Education Quality Assurance, Part 3, pp:97-106. 